Int. J. Biometeor. 1973, vol. 17, number 4, pp. 337-343

\title{
Analysis of Stomatal and Convective Resistances to Transpirational Flow
}

\author{
by \\ S.I. Ajiri*, J.T. Clayton and C.S. Chen**
}

\begin{abstract}
INTRODUCTION
Water loss and carbon dioxide exchange between the plant and its environment occur mainly through stomates. The processes are each affected by diffusive resistances due to the stomates and to the external boundary layer. The desire to reduce the amount of water transpired during the production of biomass and to minimize excess transpired water loss from a watershed has spurred on research to further understand and control the resistances to transpirational flow.
\end{abstract}

Brown and Escombe (1900) pioneered work in stomatal control of transpiration and calculated that the resistance in a single circular tube was the sum of the resistances due to the tube length and to the two mirror-image diffusional shells on either side of the tube. Their result has been reconfirmed theoretically by Patlak (1959) and more recently by Parlange and Waggoner (1970). When the calculation was applied to predict transpiration rates from leaves or multiperforate septa, the values were several times in excess of measured values. In order to explain the discrepancy, Brown and Escombe (1900) suggested that initial interference of flow lines when the stomates were wide open increased the stomatal resistance. Although relevant discussion on mutual interference has resulted since 1900 (see Parlange and Waggoner, 1970) it is now known that Brown and Escombe's problem lay in the fact that they made no allowance for the external boundary layer resistance. Other investigators agree that an external resistance has to be taken into consideration whether or not stomatal resistance is limiting. Bange (1953) described the resistance as the adhering air layer while Lee and Gates (1964) called it the "hypothetical motionless air layer of a calculable thickness over the leaf". In general, the air surrounding a transpiring leaf is never stagnant because of natural or forced convection. Consequently, convective terms should be included in the diffusive equation which yields the boundary layer resistance. This paper aims at developing a mathematical model to predict transpiration rates and, from first principles of engineering mass transfer, to determine mass transfer coefficients which combine the effects of diffusion and convection.

\section{PHYSICAL MODEL}

The transport of water vapor from the leaf to the outside environment takes place in the presence of radiant energy, because a moisture density gradient exists between the more or less moisture-saturated air in the open intercellular spaces of the leaf and the atmospheric air. If the stomates, found mostly in the

*) Biological Station, University of Michigan, Ann Arbor, Mich., USA.

**) Food \& Agricultural Engineering Department, University of Massachusetts, Amherst, Mass., USA.

Presented at the Sixth International Biometeorological Congress, Noordwijk, The Netherlands, 3-9 September 1972. 
lower leaf surface, are open, the vapor will diffuse through them. By combining Fick's diffusion law and Stefan's diameter law, Brown and Escombe (1900) obtained the following relation for the diffusion rate through a stomate pore:

$$
\mathrm{M}_{\mathrm{m}}=\frac{\mathrm{D}\left(\pi \mathrm{r}^{2}\right) \Delta \mathrm{C}}{\mathrm{L}}+\mathrm{D}(2 \mathrm{r}) \Delta \mathrm{C}
$$

With $\mathrm{N}$ per $\mathrm{cm}^{2}$ as stomatal density, the average moisture flux, $\dot{\mathrm{M}}_{\mathrm{m}}$, is given by

$$
\dot{M}_{\mathrm{m}}=\frac{\Delta \mathrm{C}}{\frac{\mathrm{L}}{\mathrm{ND}^{\pi} \mathrm{r}^{2}}+\frac{1}{\mathrm{ND} 2 \mathrm{r}}}
$$

-A close examination of eqn (1) exposes the erroneous "diameter law" which is repeatedly found in plant physiology literature (Ting and Loomis, 1963). This law suggests that diffusion through small pores is proportional to their diameter. This is the case only when $L=O$. In nature, however, $L$ is generally greater than 2r (Meidner and Mansfield, 1968), which implies that stomatal conductance is directly proportional to the pore area and inversely proportional to its length. Thus, at any given epidermal thickness, $L=$ constant, the conductance is proportional to the cross-sectional area of the pore. An intermediate condition in which the pore length is approximately equal to the maximum diameter suggests that as the stomate begins to close, its diameter becomes small relative to the epidermal thickness, and the stomatal conductance becomes proportional to the area. Figure 1 is a plot of stomatal conductance versus pore radius. It stresses the area proportionality and points out the fact that stomatal control is greater at larger openings. The curve will always remain concave upwards irrespective of the slope and density of the stomate. The convex upward curve drawn by Bange (1953) for a hyperbolic-shaped stomate omitted the $(1 / r)$ term of eqn (1).

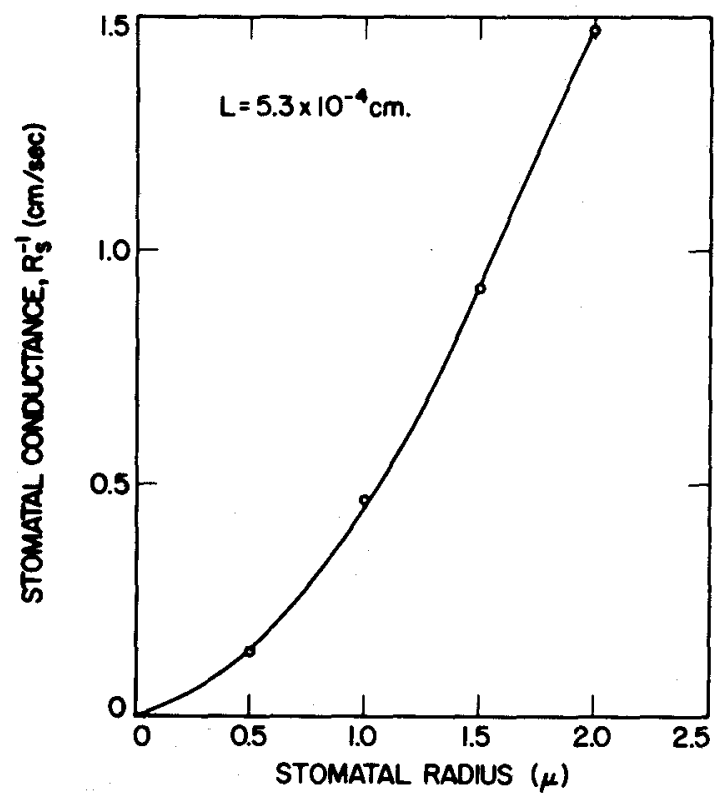

Fig. 1. Stomatal conductance vs stomatal radius. 
The concentration difference, $\Delta \mathrm{C}$, between the ends of the stomatal length is given by $\left(\mathrm{C}_{\mathrm{mi}}-\mathrm{C}_{\mathrm{mo}}\right)$, where $\mathrm{C}_{\mathrm{mi}}$ and $\mathrm{C}_{\mathrm{mo}}$ are respectively the concentrations in the intercellular air and at the surface of the leaf. When the leaf is well supplied with water, the air in the intercellular space is assumed to be saturated with water vapor so that the $\mathrm{C}_{\mathrm{mi}}$ corresponds to the saturated water vapor concentration at the leaf temperature.

Gaastra (1959) has pointed out that it is impossible to prove by direct measurements that the air in the intercellular space is saturated with water vapor. Observing no decrease in the transpiration rate of intact cucumber leaves exposed for several hours to high light intensities, he accepted the assumption of saturated intercellular space as approximately correct. The moisture concentration at the leaf surface lies between the moisture content in the intercellular air space and that in the air surrounding the leaf. Although moisture concentration at the leaf surface cannot be measured, it can be expressed in terms of the free stream value of moisture concentration.

Under steady state conditions, the total average mass flux across the stomatal thickness is the same over the external boundary layers. Thus

$$
\dot{\mathrm{M}}_{\mathrm{m}}=\frac{\mathrm{C}_{\mathrm{mi}}-\mathrm{C}_{\mathrm{mo}}}{\frac{\mathrm{L}}{\mathrm{ND} \pi \mathrm{r}^{2}}+\frac{1}{\mathrm{ND}(2 \mathrm{r})}}=\overline{\mathrm{h}}_{\mathrm{m}}\left(\mathrm{C}_{\mathrm{mo}}-\mathrm{C}_{\mathrm{m}^{\infty}}\right)
$$

where $C$ is the free stream value of moisture concentration and $\overline{\mathrm{h}}_{\mathrm{m}}$ is by definition the average mass transfer coefficient. Eliminating $\mathrm{C}_{\mathrm{mo}}$ and rearranging the above equation we obtain

$$
\dot{\mathrm{M}}_{\mathrm{m}}=\frac{\mathrm{C}_{\mathrm{mi}}-\mathrm{C}_{\mathrm{m}^{\infty}}}{\frac{\mathrm{L}}{\mathrm{ND}{ }^{\pi} \mathrm{r}^{2}}+\frac{1}{2 \mathrm{NDr}}+\frac{1}{\bar{h}_{\mathrm{m}}}}
$$

Equation (3) is the average transpirational flux in terms of the concentration difference across the stomates and external boundary layer and is a function of three resistances to diffusion. The first two resistances, as noted earlier, are respectively resistance to diffusion along the stomatal length and the resistance to diffusion due to the diffusional shells at either end of the pore. They depend on stomatal geometry and distribution on the leaf and together constitute the stomatal resistance, $R_{S}$, to transpiration. The third resistance, due to convection, depends on the shape and size of the leaf, the presence of other leaves, and the flow conditions around the leaf; it is known as the boundary layer resistance, $R_{a}$.

\section{CORRELATION}

Raschke (1956) showed that the air flow over a leaf can be idealized to flow over a flat plate without appreciable error. Through experiments, he further showed that such flow is basically laminar for forced convection over the leaf a few centimeters long. Ajiri (1970) obtained the following expression for the concentration boundary layer thickness, $\delta \mathrm{c}$ :

$$
\frac{\delta_{c}}{\mathrm{x}}=\sqrt{\frac{2 \mathrm{M}}{\mathrm{M}_{\mathrm{m}}} \frac{1-\mathrm{Q}}{\mathrm{Qf}} \mathrm{f}_{2}(\mathrm{P})} \cdot \sqrt{\frac{1}{\mathrm{Re}}}
$$


The mass flux at any length, $x$, is given by

$$
\mathrm{M}_{\mathrm{mo}}=\mathrm{h}_{\mathrm{m}}\left(\mathrm{C}_{\mathrm{m}^{\infty}}-\mathrm{C}_{\mathrm{mo}}\right)=\mathrm{D} \frac{\mathrm{C}}{\mathrm{C}-\mathrm{C}_{\mathrm{mo}}}\left(\frac{\mathrm{dC}}{\mathrm{dy}}\right)_{\mathrm{o}}
$$

Described as a dimensionless mass transfer coefficient, the above expression becomes

$$
\frac{\mathrm{h}_{\mathrm{m}} \mathrm{X}}{\mathrm{D}}=\mathrm{Z} \frac{\mathrm{C}}{\mathrm{C}-\mathrm{C}_{\mathrm{mo}}} \quad \frac{1}{2} \frac{\mathrm{M}_{\mathrm{m}}}{\mathrm{M}} \frac{\mathrm{Qf}_{2}(\mathrm{P})}{1-\mathrm{Q}} \cdot \quad \mathrm{Re}
$$

The results are summarized in Table 1.

TABLE 1. Solution of boundary layer equations for velocity and concentration in cases involving absorption and evapotranspiration of water vapor across the laminar boundary layer over a flat plate imbedded in

\begin{tabular}{|c|c|c|c|c|c|c|c|c|c|}
\hline$Q$ & $\beta$ & $\mathrm{P}$ & ${ }^{\delta} \mathrm{c}^{\prime \delta}$ & $\frac{\delta_{c}}{\mathrm{X}} \breve{R}_{\mathbf{e}}$ & $\frac{\delta}{\mathrm{x}} \sqrt{ } \mathrm{R}_{\mathrm{e}}$ & $\frac{\mathrm{V}^{\infty}}{\mathrm{U}^{\infty}} / \mathrm{R}_{\mathrm{e}}$ & $\frac{h_{m} x}{D}$ & $\frac{\mathrm{C}-\mathrm{C}_{\mathrm{m}}}{\mathrm{C}} \frac{1}{\sqrt{\mathrm{R}_{\mathrm{e}}}}$ & Remarks \\
\hline-3 & 0.666 & -1.010 & 2.062 & 4.95 & 2.40 & -0.277 & & 0.606 & $\begin{array}{l}\text { evapotran- } \\
\text { spiration }\end{array}$ \\
\hline-1 & 0.5 & -0.663 & 1.436 & 4.50 & 3.13 & 0.171 & & 0.444 & $"$ \\
\hline-0.2 & 0.156 & -0.166 & 1.238 & 5.26 & 4.25 & 0.703 & & 0.304 & $"$ \\
\hline 0 & 0 & 0 & 1.203 & 5.59 & 4.64 & 0.870 & & 0.269 & $\begin{array}{l}\text { critical } \\
\text { point }\end{array}$ \\
\hline 0.2 & -0.204 & 0.180 & 1.163 & 5.96 & 5.13 & 1.060 & & 0.235 & absorption \\
\hline 1 & -2.0 & 0.985 & 1.063 & 8.19 & 7.71 & 2.011 & & 0.122 & " \\
\hline 3 & $-\infty$ & 3.000 & 1.000 & $\infty$ & $\infty$ & $\infty$ & & 0 & $"$ \\
\hline
\end{tabular}
moist air

The ratio $\delta_{\mathrm{c}} / \delta$ is unity for evapotranspiration but increases to 2 during absorption with large partial density differences. At $Q=0$, which implies that the convective velocity $v_{0}$ is zero at the plate surface,

$$
\frac{\delta_{c}}{\mathrm{X}}=\frac{5,59}{\operatorname{Re}}
$$

and

$$
\frac{\delta}{\mathrm{X}}=\frac{4.64}{\sqrt{\mathrm{Re}}}
$$

Equations (6) and (7) are approximate solutions for the concentration and hydrodynamic boundary layer thicknesses respectively when mass transfer occurs by diffusion only. However, a convective velocity, vo, exists in the outer portion of the boundary layers because of the presence of the hydrodynamic boundary layer. It constitutes a small percentage of the mainstream velocity. Its value decreases during absorption but increases during evapotranspiration and approaches infinity as boiling is reached. 
The dimensionless mass transfer coefficient, $\mathrm{h}_{\mathrm{m}} \mathrm{x} / \mathrm{D}$, depends on the partial density ratio $\left(\mathrm{C}-\mathrm{C}_{\mathrm{mo}}\right) / \mathrm{C}$ and on the parameters $\alpha, \beta$ and Re. It appears in Table 1 in the dimensionless form $\frac{\left(\mathrm{h}_{\mathrm{m}} \mathrm{x}\right)}{\mathrm{D}} \frac{\left(\mathrm{C}-\mathrm{C}_{\mathrm{m}}\right)}{\mathrm{C}} \frac{1}{\sqrt{\mathrm{Re}}}$ whose value increases during absorption and decreases during evapotranspiration to a zero value at $Q=3$. The partial density of the air at the wall is zero at $Q=3$ which implies boiling-water surface. Note, however, that $\mathrm{h}_{\mathrm{m}} \mathrm{x} / \mathrm{D}$ still has a firite value when $Q=3$ even though the partial density relation $\mathrm{C} /\left(\mathrm{C}-\mathrm{C}_{\mathrm{mo}}\right)$ may be infinite.

Once the mass transfer coefficient, $h_{m}$, has been determined, its value can be used to evaluate the boundary layer resistance, since

$$
\mathrm{R}_{\mathrm{a}}=\frac{1}{\mathrm{~h}_{\mathrm{m}}}
$$

When $R_{a}$ is negligibly small, the shape of the overall leaf conductance versus pore radius is concave upward as for stomatal conductance. As $R_{a}$ increases, the total leaf conductance curve will tend to become linear with stomatal radius. $R_{\mathrm{a}}$ increases as the length of the object is increased and as the windspeed is decreased. Hence, for an object of constant characteristic length, $R_{a}$. will be greatest in calm air. If $R_{a}$ is the dominant resistance, the leaf conductance curve is convex upward. Figure 2 illustrates the effect of variable boundary layer resistance on the total leaf conductance curve. Conversely, when $R_{a}$ is fixed, the effect of $R_{S}$ can be studied.

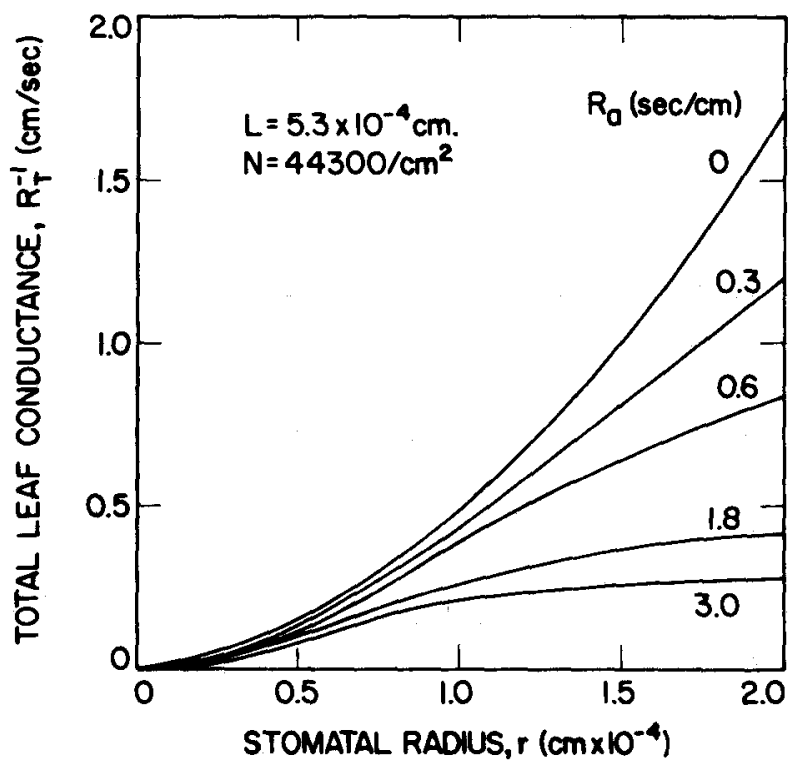

Fig. 2. The effect of variable boundary layer resistance on total leaf conductance. 


\section{REFERENCES}

AJIRI, S.I. (1970)

: An analytical and experimental study of convective mass transfer from a transpiring leaf. Unpublished Ph.D. dissertation, Amherst, Mass., Food \& Agric. Eng. Dept., Univ, of Mass.

BANGE, G.G.J. (1953) : On the quantitative explanation of stomatal resistance, Acta Bot. neerl., 2: 255-299.

BROWN, H.T. and ESCOMBE, F. (1900): Static diffusion of gases and liquids in relation to the assimilation of carbon and translocation in plants. Phil. Trans. B., 193: 233-291.

GAASTRA, P. (1959) : Photosynthesis of crop plants as influenced by light, carbon dioxide, temperature and stomatal diffusion resistance. Mededelingen Landbouwhogeschool, Wageningen, 59:1-68.

LEE, R. and GATES, D.M. (1964): Diffusion resistance in leaves as related to their stomatal anatomy and micro-structure. Amer. J.Bot., $51: 963-975$.

MEIDNER, H. and MANSFIELD, T.A. (1968) : Physiology of Stomata. MeGrawHill, New York.

PARLANGE, J.Y. and WAGGONER, P.E. (1970): Stomatal dimensions and resistance to diffusion. Plant Physiol., 46:337 342.

PATLAK, C.S. (1959) : A contribution to the study of diffusion of neutral particles through pores. Bull. Math. Biophys., 21: 129-140.

RASCHKE, K. (1956) : Über die physikalischen Beziehungen zwischen Wärmeübergangszahl, Strahlungsanstausch, Temperatur und Transpiration eines Blattes. Planta, 48: $200-238$.

TING, I. P. and LOOMIS, W.E. (1963): Diffusion through stomates. Amer. J. Bot., 50: 866-872.

\section{NOMENCLATURE}

$\mathrm{C}=$ concentration (also partial density), $\mathrm{gm} / \mathrm{cm}^{3}$

$\mathrm{D}=$ diffusion coefficient, $\mathrm{cm}^{2} / \mathrm{sec}$

$\mathrm{h}_{\mathrm{m}}=$ local mass transfer coefficient, $\mathrm{cm} / \mathrm{sec}$

$\overline{\mathrm{h}}_{\mathrm{m}}=$ average mass transfer coefficient, $\mathrm{cm} / \mathrm{sec}$

$\mathbf{K}=\alpha \beta \mathbf{Z}$

$\mathrm{L} .=$ stomatal length, $\mathrm{cm}$

$\mathrm{M}=$ molecular weight

$\mathrm{M}=$ mass flow rate, $\mathrm{gm} /\left(\mathrm{cm}^{2} \cdot \mathrm{sec}^{1}\right)$

$\mathrm{N}=$ stomatal density, $1 / \mathrm{cm}^{2}$.

$P=\frac{3 . K(\delta / \delta c)}{K(\delta / \delta c)-4}$

$\mathrm{Q}=3-2 \mathrm{Z}$

$\mathrm{R}$ = resistance, sec $/ \mathrm{cm}$

Re $=$ Reynolds number, $\mathrm{u}^{\infty} \mathrm{x} / \mathrm{v}$

$r$ = stomatal radius, $\mathrm{cm}$ 
$\mathrm{u}=$ velocity parallel to surface, $\mathrm{cm} / \mathrm{sec}$

$\mathrm{v}=$ velocity normal to surface, $\mathrm{cm} / \mathrm{sec}$

$\mathrm{x}=$ distance along surface from leading edge, $\mathrm{cm}$

$\mathrm{y}=$ distance normal to surface, $\mathrm{cm}$

$\mathrm{Z}=\frac{2-\sqrt{4-6 \beta}}{\beta}$

$\alpha=$ dimensionless ratio $\frac{\mathrm{D}}{\mathrm{M}}$

$\beta=$ dimensionless ratio $\frac{\mathrm{C}_{\mathrm{m}^{\infty}}-\mathrm{C}_{\mathrm{mo}}}{\mathrm{C}-\mathrm{C}_{\mathrm{mo}}}$

$\delta=$ hydrodynamic boundary layer thickness, $\mathrm{cm}$

$\delta_{c}=$ concentration boundary layer thickness, $\mathrm{cm}$

$\rho=$ density, $\mathrm{gm} / \mathrm{cm}^{3}$

$\nu \quad=$ kinematic viscosity, $\mathrm{cm}^{2} / \mathrm{sec}$

$\mu=$ dynamic viscosity

\section{SUBSCRIPTS}

$$
\begin{aligned}
& \mathrm{a}=\text { main flow gas (air) } \\
& \mathrm{i} \quad=\text { intercellular space in leaf } \\
& \mathrm{m} \quad=\text { diffusing gas (water vapor) } \\
& \mathrm{o}=\text { wall } \\
& \mathrm{s} \quad=\text { stomatal } \\
& \infty \quad=\text { free stream }
\end{aligned}
$$

